\title{
Tumours of the central nervous system in children
}

\author{
PETER O. YATES \\ From the Department of Pathology, University of Manchester
}

SYNOPSIS One hundred and fifty-five tumours of the central nervous system which occurred in children in the north west of England during a period of nine years are analysed from a pathological $\vec{\omega}$ point of view. It is probable that these represent over $90 \%$ of all such tumours occurring in the region at that time and that the relative incidence of various tumour types is, therefore, a true one:? just over a fifth (35) were medulloblastomas; just under a fifth (29) were juvenile astrocytomas; $a . \overrightarrow{.}$ similar group (33) were of the adult astrocytic type; there were 24 ependymomas and 34 in miscellaneous minor groups.

It can probably be assumed that all children with tumours of the central nervous system are eventually seen in hospital. If this is so, then the Children's Tumour Registry for the north-west of England includes practically all such tumours which have occurred during the past nine years and, because of the cooperation of the pathologists of the region, material from biopsy or necropsy is available for study. The unselected nature of this series of tumours gives it a statistical validity as to the relative incidence of different tumour types not shown in much larger samples which have accumulated in specialist hospitals or neurosurgical departments. Even in this Registry, not all the cases were confirmed pathologically; however, doubts are almost confined to brain-stem gliomas where 10 diagnoses still rest on clinical evidence alone.

There remain 155 tumours of the central nervous system which have presented during eight years; they can conveniently be split into five more or less equal groups (Table). The first and slightly the largest group is the medulloblastoma; the second is what is now known as the juvenile astrocytoma, but since its properties are very different from the ordinary adult astrocytoma I would prefer a descriptive non-committal name like piloid glioma; the third consists of adult forms of astrocytoma and glioblastoma; the fourth of tumours of the ependyma, and the fifth of the remainder.

It is unfortunately true, as this survey shows, that the majority of children with tumours of the central nervous system do not survive for long. Of the 155 cases, just over 50, or one-third, are alive today. Surprisingly, considering their rapid rate of growth, about one-third of the patients with medulloblastoma are alive, presumably because of the

\begin{tabular}{|c|c|c|c|c|}
\hline \multirow[b]{2}{*}{ Tumour Type } & \multicolumn{2}{|c|}{ T A B L E } & \multirow[b]{2}{*}{ Female } & \multirow[b]{2}{*}{ Total } \\
\hline & $\begin{array}{l}\text { State of } \\
\text { Patient }\end{array}$ & Male & & \\
\hline Medulloblastoma & $\begin{array}{l}\text { Alive } \\
\text { Dead }\end{array}$ & $\begin{array}{r}8 \\
21\end{array}$ & $\begin{array}{l}2 \\
4\end{array}$ & 35 \\
\hline Juvenile astrocytoma & Alive & $\begin{array}{l}8 \\
8\end{array}$ & $\begin{array}{l}9 \\
4\end{array}$ & 29 \\
\hline Adult astrocytoma & Alive & 2 & 4 & 33 \\
\hline & Dead & 15 & 12 & \\
\hline Ependymoma & $\begin{array}{l}\text { Alive } \\
\text { Dead }\end{array}$ & $\begin{array}{l}5 \\
6\end{array}$ & $\begin{array}{r}1 \\
12\end{array}$ & 24 \\
\hline Miscellaneous & Alive & 7 & 7 & 34 \\
\hline $\begin{array}{l}\text { Lipoma 2, } \\
\text { Meningioma 3, } \\
\text { Rathke 8, } \\
\text { Pituitary adenoma 2, } \\
\text { Teratoma 6, } \\
\text { Pinealoma 4, } \\
\text { Melanoma 1, } \\
\text { Microglioma 1, } \\
\text { Unclassified } 7\end{array}$ & Dead & 12 & 8 & \\
\hline
\end{tabular}

excellence of modern radiotherapeutic treatment of these tumours. Furthermore, two-thirds of theo patients with juvenile astrocytoma are doing well after surgical treatment. Indeed there is somes evidence (not from Registry cases) that incomplete removal of cerebellar astrocytomas might be folos lowed by no sign of further trouble for 10,15 , on more years. It is possible that the growth of some of these tumours ceases or slows down in latef years if the patient can be helped to survive to adult life. We know from a study of a much larger series (140) of these piloid gliomas that nearly half of tho patients are alive 10 years after operation, which has often been of a limited kind. Of all other groups few remain alive; this is particularly surprising io the cases of ependymal tumours which do nof always show the histological appearance of verf active growth.

In all the tumour types but one, the sex incidenceg 
is about equal; the exception, of course, is the medulloblastoma, which is essentially a male tumour, there being in this series about five times as many cases in boys as in girls. (In a larger series of 160 medulloblastomas, we have found the ratio nearer 3 to 1.) The medulloblastoma also occurs at a somewhat younger age than other tumours; it can be safely said that a boy under 5 years of age with signs of a tumour in the posterior fossa almost certainly has a medulloblastoma, whereas, if it were a girl, the diagnosis would be either juvenile astrocytoma of the cerebellum or an ependymoma.

The medulloblastomas in this series showed few

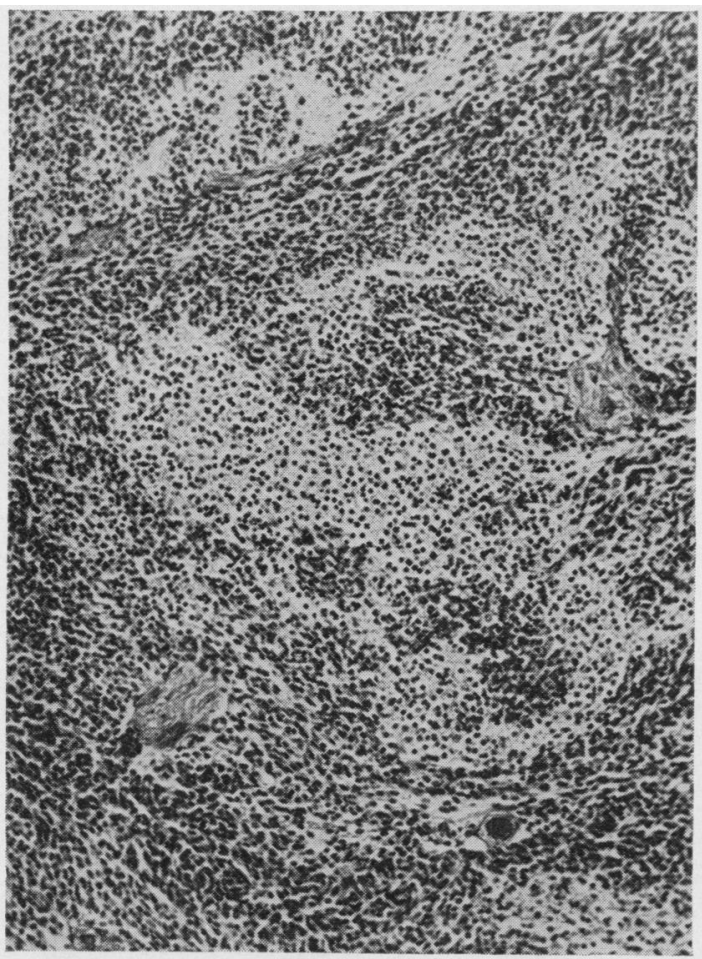

FIG. 1. Medulloblastoma showing mosaic pattern due to partial differentiation and production of glial fibres in the pale areas. Haematoxylin and eosin $\times 140$.

positive diagnostic features, many being seen as an actively growing small spindle-celled tumour with little recognizable pattern and in these the diagnosis has been largely presumptive. Perhaps the commonest feature which others have shown is a mosaic pattern (Fig. 1), made up of areas dense with tumour nuclei and paler areas where the nuclei are separated by greater amounts of cytoplasm and by fibrillary processes, which is taken as evidence of some degree of glial differentiation. It is sometimes possible to

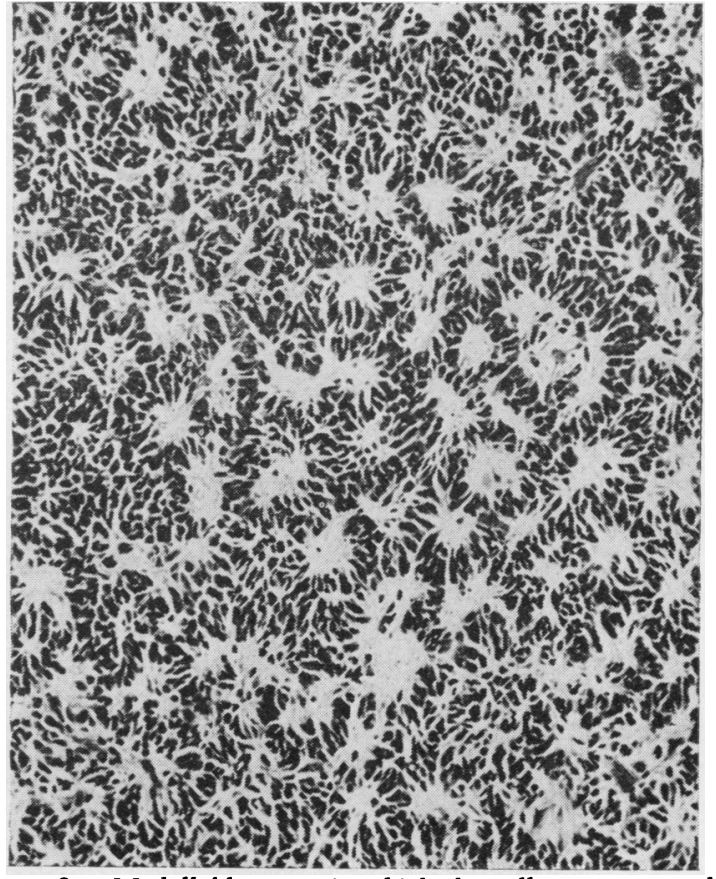

FIG. 2. Medulloblastoma in which the cells are arranged to form rosettes, the centre of which is occasionally occupied by a large astrocyte. Haematoxylin and eosin $\times 180$.

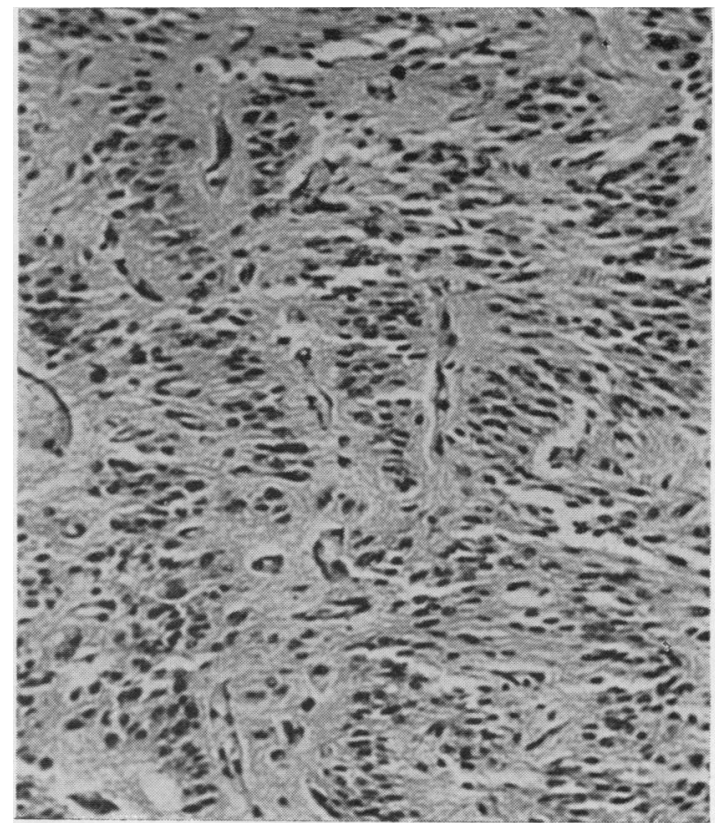

FIG. 3. Medulloblastoma. Spindle-shaped, fibre-forming cells are arranged in a pallisaded manner. Haematoxylin and eosin $\times 180$. 
see that the cells have a characteristic carrot shape with a fibrillary tail and these might be arranged as palisades or columns. The appearance of rosettes, a feature which medulloblastomas are often said to share with neuroblastomas, has been uncommon. Two tumours showed rosettes (Fig. 2) and two others had a rippling palisaded pattern which, since the columns of cell bodies are separated by fibrous processes, might be considered a series of elongated rosettes (Fig. 3). The evidence available suggests that all the medulloblastomas had arisen in the neighbourhood of the cerebellar vermis. These tumours, of course, seed widely in the ventricles and in the subarachnoid space so that their point of origin is not always clear.

My second group was the piloid gliomas or 'juvenile astrocytomas', as they are often called. The most frequent site for these is the cerebellum where they may simply be called cerebellar astrocytomas, but they occur also in the optic nerve and chiasma where they may be called optic nerve gliomas, or in the hypothalamus where they are sometimes known as infundibulomas. Despite these many varied names, this group of tumours, together with a small number from other sites. share many biological and histological features not found in adult astrocytic tumours. For instance, unlike the adult type, they show a varied histological picture from field to field which makes low-power recognition quite easy. The primary tissue is composed of fusiform cells with hair-like glial fibres usually emerging from the poles of the cells; these fibres show a tendency to form streams and bundles which somewhat resemble tresses of hair, hence the term 'piloid'. Between the bundles, a spider's web type of tissue develops as a result of hydropic changes in the cells and accumulation of fluid between fibres. The tumour cells are here more stellate and occasionally resemble mature astrocytes. Areas of this kind break down to form microcysts which may coalesce to become large cavities.

One characteristic feature which almost all piloid gliomas show whatever their site is the presence of Rosenthal bodies or fibres. In glial tissue, particularly in glial tumours, some swelling and eosinophilia of fibres is not uncommon. The appearance of Rosenthal bodies is so characteristic, however, that it is not difficult to distinguish them from such general degenerative changes. They are refractile, acidophilic objects of a peculiar shape (Fig. 4). At one end they usually have a globoid swelling; the other end commonly tapers to the diameter of a glial fibre with which they can sometimes be seen to merge. Occasionally, probably when cut obliquely, they appear as ovoid or sausage-shaped bodies, sharply defined and in these circumstances lacking

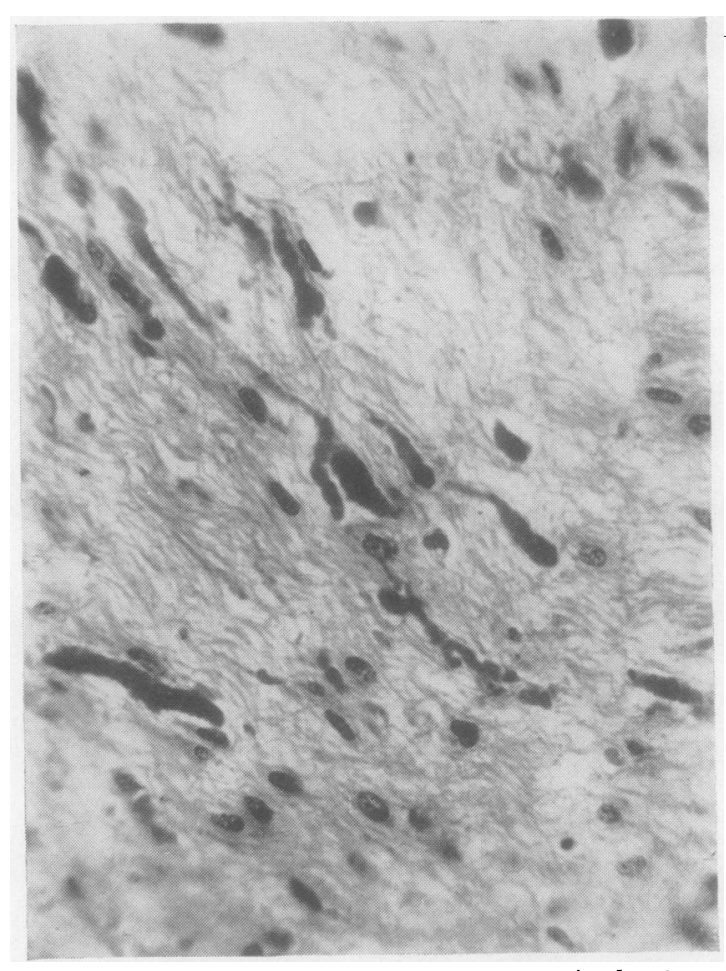

FIG. 4. Piloid glioma (juvenile astrocytoma) showing a dense felt-work of fine glial fibres amongst which lie $a$ number of tadpole-shaped Rosenthal bodies. Haematoxylin and eosin $\times 600$.

any glial fibre connexions. Their size varies widely; the globoid 'head' may be as large as $25 \mu$ across, whilst their length before junction with a glial fibre may reach $100 \mu$. Many smaller forms can be found. They often have a regularly beaded or coarsely granular appearance and sometimes appear to be laminated in an onion-like manner. They show a marked affinity for iron-haematoxylins, acid fuchsin and acidic dyes and they are relatively easily impreg- $\frac{D}{0}$ nated with silver and gold. The piloid gliomas rarely show any evidence of particularly active $N$ growth although invasion of overlying meninges is $N$ almost invariable and vascular proliferation, which is usually a feature of malignant glial tumours, is ${ }_{0}^{\omega}$
common.

The third group ( 33 cases) consisted of the adult ${ }^{\circ}$ type of astrocytic tumour which occurs also in childhood and, as in the adult, is more commonly found in the cerebral hemispheres than in the cerebellum. This type of tumour shows none of the patterns of the piloid gliomas and cystic changes $\frac{?}{\mathbb{D}}$ occur in a uniform field of more or less stellateo astrocytes. Various degrees of active growth and pleomorphism occur up to the fully developedo 
glioblastoma. In 11 children, this kind of astrocytic tumour was found infiltrating the brain-stem. In some, growth appears to have been quietly insidious causing very little disturbance of function but merely expanding the tissue of the pons or medulla until eventually compression or distortion could no longer be accommodated. Most are more actively malignant. A possible 10 further tumours of this type and situation occurred but have not yet been confirmed pathologically. This frequency of brain-stem tumours is in marked contrast to that in the adult.

Both these last two groups, that is to say, the juvenile astrocytoma (piloid glioma) and the adult form of astrocytic tumour occurring in childhood, show an abnormal distribution of $\mathrm{ABO}$ blood groups in that there is a marked excess of group A and few cases with blood group $O$. We have been able to confirm this in a much larger group of cases of tumour in Manchester; in our experience, no other group of cerebral tumours shows such a change.

The fourth big group is the ependymomas. Although the impression of these is of histologically relatively inactive tumours, only about one-fifth of

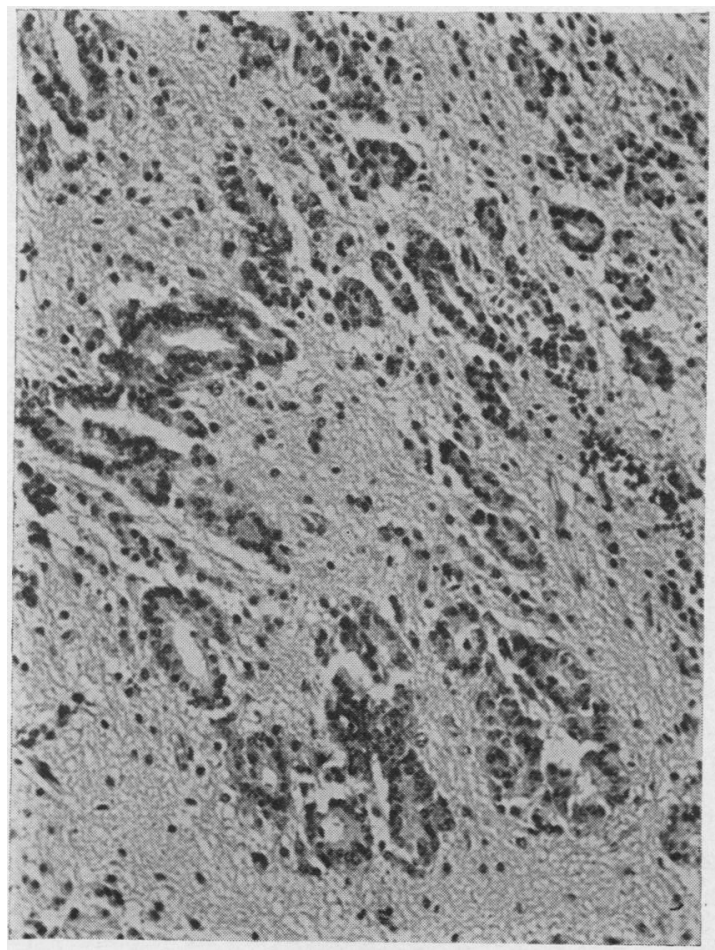

FIG. 5. Well-formed epithelial clefts in an ependymoma which showed very little fibre-forming or glial differentiation. Haematoxylin and eosin $\times 180$. the patients are alive to-day. This may be partly due to the site of these tumours which, whether they arise in spinal cord, fourth ventricle, aqueduct, or wall of the third ventricle, must be close to important and vital structures. But it is not the sole factor, for the brain of a child seems able to accommodate well to the presence of slowly growing tissues wherever it is and even to the apparent destruction of areas which in an adult would be vital. Ependymomas are predominantly epithelial or glial, depending on whether differentiation emphasizes the one or the other end of the cell. In some cases, of course, both aspects are represented. The epithelial-lined cavities are occasionally very obvious features (Fig. 5) or they may be hard to discover in a tumour which consists, for the most part, of sheets of disordered cells (Fig. 6). Most common is the presence of glio-vascular systems (Fig. 7), in which rosettes of glial cells surround blood vessels, their fibrous processes being radially or concentrically arranged. Rarely, the nucleated end of these cells lines an epithelial cleft.

The majority of the ependymomas in the Registry are of a type which has sometimes been called subependymoma. The reason for this appears to be

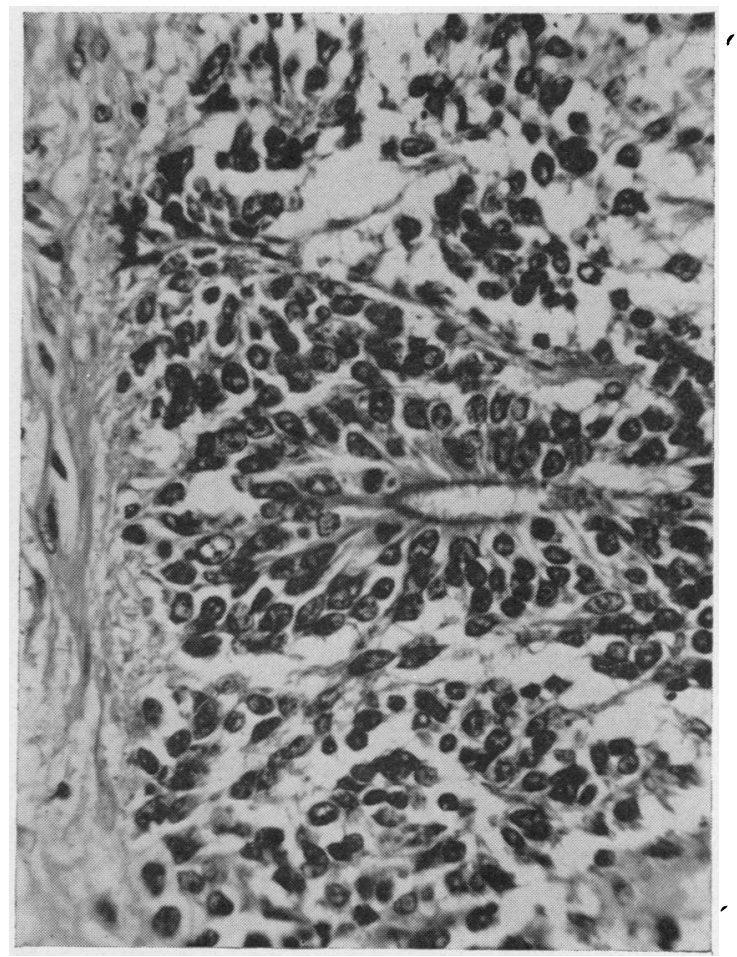

FIG. 6. Ependymoma which consisted mostly of unpatterned masses of cells but in which rare epithelial clefts could be found. Haematoxylin and eosin $\times 400$. 


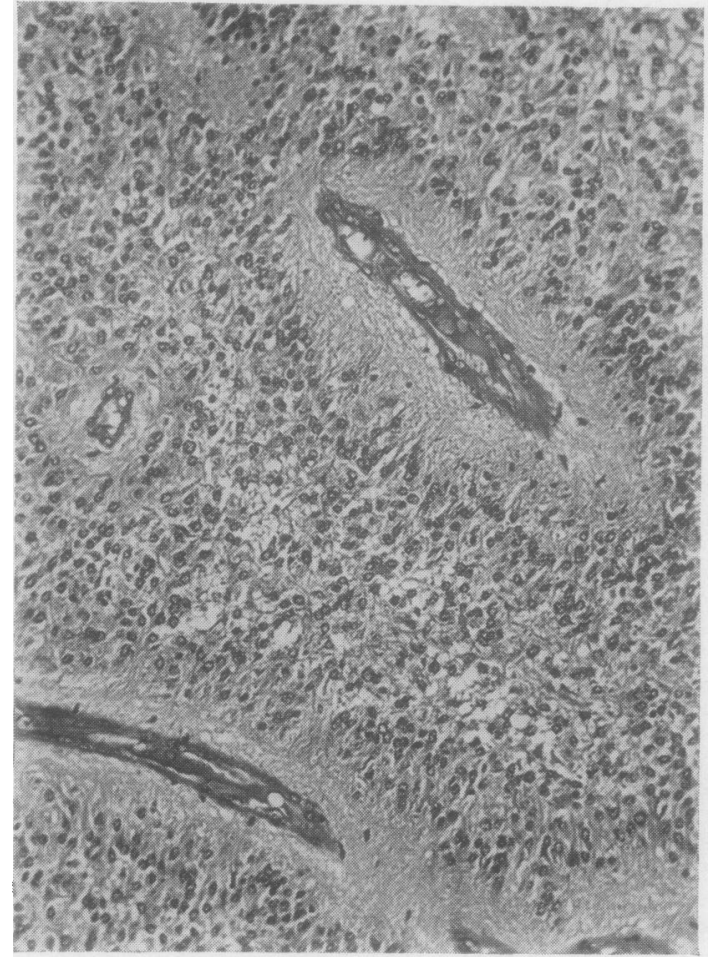

FIG. 7. Glio-vascular systems in an ependymoma showing no epithelial differentiation. Haematoxylin and eosin $\times 160$.

that the tissue composing them resembles that found heaped up beneath ventricular linings in inflammatory conditions or is seen replacing the central canal of the cord in adults. It consists of clusters of nuclei from which stream glial fibres to run sometimes towards a vascular or connective tissue strand not always with any clear radial orientation. Sometimes these glial fibre zones surround a vessel completely when the cell nuclei appear to stand off at a distance (Fig. 8). These tumours rarely show epithelial clefts and are often found in the cerebellopontine angle, having escaped from the lateral angle of the fourth ventricle. The frequent presence of a few mitotic figures in the cellular patches should hint at their malignant nature, which the poor survival rate would indicate.

The miscellaneous fifth of this series includes eight tumours originating in Rathke's pouch. These are mostly composed of adamantinoma-like epithelial clumps growing slowly in the floor of the third ventricle and the hypothalamus, which they may eventually almost completely replace; only four

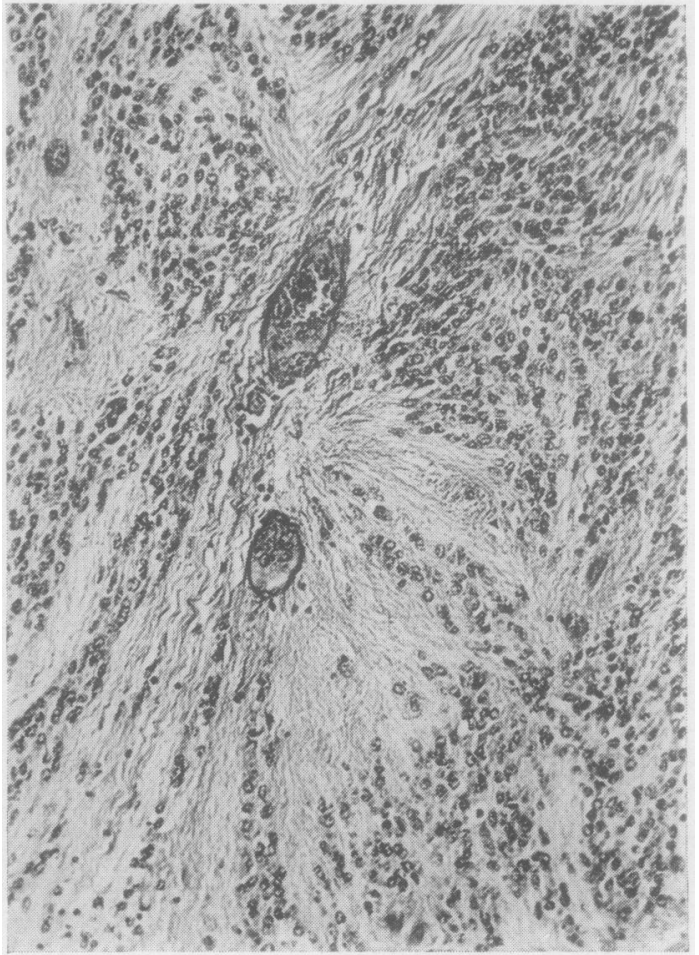

FIG. 8. Ependymoma showing the irregular glio-vascular systems and clustered nuclei which characterize the 'subependymal glioma'. Haematoxylin and eosin $\times 160$.

patients remain alive. The unusual thing about these tumours is the dense glial tissue which encloses the epithelial structures and which often forms the bulk of the tumour. This gliosis is of a peculiar kind, resembling that of the piloid gliomas of cerebellum, optic nerve, or hypothalamus. This resemblance includes the presence of numerous Rosenthal bodies which are not usually found in glial response to chronic irritation, even by the squamous epithelium $I$ in dermoids and teratomas elsewhere in the central nervous system. These appearances suggest that $N$ Rathke pouch tumours are mixed glio-epithelial tumours in the sense that fibroadenomas of the breast or perhaps some salivary gland tumours are.

It is possible to divide children's cerebral tumours into five more or less equal groups and two of these $\varphi$ have a hopeful prognosis if treatment is appro- $\mathbb{D}$ priate and adequate: for the medulloblastomas, radiotherapy, and for the juvenile astrocytomas, surgery. There is, therefore, more than academic interest in classifying these tumours and attempting to reach an accurate diagnosis. 